\title{
Sustainable Layout Planning Methods for Taxi Service Centres: A Case Study of Jiangning District, Nanjing
}

\author{
Zhenjun ZHU, Xiucheng GUO, Jun ZENG, Yibang ZHANG, Zhaoguo HUANG
}

\begin{abstract}
Taxi fleet size has undergone a continuous rapid growth in Chinese cities, while the service facility layout planning has relatively lagged behind, causing a decrease in the service quality. Therefore, it is crucial to carry out taxi service centre layout planning. This study analyses the functional orientation and hierarchical layout mode of taxi service centres, and then proposes stepwise layout planning methods combining existing transportation facilities. Considering the demand for integrated service centres is relatively low and convenient service centres are highly flexible, their layout can be determined by qualitative analysis. The constrained layout model of functional service centres is established by optimizing the layout scheme among various alternative taxi service centres. The study finds the model is a mixed $0-1$ integer programming problem, genetic algorithms are applied to solve it. Finally, the proposed methods are applied to a real case of Jiangning district, Nanjing. The results show that one integrated service centre, four functional service centres, and twenty-three convenient service centres could satisfy taxi drivers' demand, which suggests that the proposed methods should effectively address the layout planning problem of taxi service centres, thus have important implications for other cities' downtown areas in China and beyond.
\end{abstract}

Keywords: constrained layout model; functional orientation; genetic algorithms; layout mode; taxi service centres

\section{INTRODUCTION}

A taxi is an indispensable transport mode in large cities, complementing other public transport modes in terms of flexible door-to-door services [1-3]. With a steady improvement in the living standards, the demand for taxis will gradually grow. The taxi service facilities are still lagging behind, and the diverse demand for taxi drivers has also not been well satisfied. The differences between taxi management modes and transportation developments have resulted in fewer planning practices of taxi service centres overseas. Although the taxi fleet size is large, service quality is relatively low in China, there is a strong demand for taxi service centre layout planning. Following the proposal by Hangzhou for setting-up an integrated service area for taxis, taxi service centres have undergone certain developments at some Chinese cities, such as Ningbo, Wenzhou, and Fuzhou. Owing to difficulties in terms of securing the land approval of the old town, planning practices are generally not ideal. The demand for taxi service centres is mainly concentrated in old town or central urban areas. To adapt to the old town renewal, ensure effective implementation, and satisfy the demand, it is crucial to conduct the study with respect to taxi service centre layout planning in old town or central urban areas.

Understanding taxi travel patterns is the promise of carrying out the layout planning of taxi service centres. A large number of studies have been conducted on taxi travel patterns [4-7], which have provided valuable insights into the patterns and mechanisms of taxi mobility. However, few studies pay attention to providing multiple service facilities for taxi drivers. While some researchers found that continuous driving may cause health problems among taxi drivers, and proposed that service facilities and economic support should be provided to taxi drivers [8-9], this is the reason that this study investigates the layout planning for taxi service centres. An essential research topic regarding service facilities location problems is to provide customers with appropriate services, including the number of facilities and optimal locations [10]. Based on the facility type and problems that policy makers should consider, researchers have proposed classical location models, such as covering problems [11-14], p-centre problems [15-17], and p-median problems [18-20], with the objective to layout service facilities for satisfying the demand generated by the network node. Extended layout models are also proposed based on classical layout models, including flow interception layout models [21-23] and competitive layout models [24-27]. However, these studies mainly focused on optimizing the layout of hydrogen or gas refuelling stations, and only meeting taxi drivers' refuelling demand [28, 29]. This study innovatively introduces the concept of taxi service centres, which aims to provide different service functions and satisfy taxi drivers' multiple demand, such as parking, dining, charging, vehicle washing, repair and maintenance, etc. Therefore, most of layout models cannot be directly applied to layout taxi service centres because taxi drivers' multiple demand is bound to correspond to different types of service centres.

To fill these research gaps, this study analyses the functional orientation and hierarchical layout mode of taxi service centres. Then, it examines the driving characteristics of taxi drivers when receiving services, adopts qualitative and quantitative analytical methods to locate taxi service centres step by step based on their rank and scale. The stepwise layout planning methods also combine with updating transportation facilities, which will revitalize stock resources to the maximum extent and promote urban sustainable transportation. Finally, the Jiangning district, Nanjing, is considered as a case study to validate the proposed methods.

\section{FUNCTIONAL ORIENTATION OF TAXI SERVICE CENTRES AND HIERARCHICAL LAYOUT MODE}

At present, there is no specific or unified definition for taxi service centres. It is also called a taxi dock, taxi service station and taxi service outlet. Though their connotations are basically consistent, they will be called taxi service centres in this study. Taxi service centres are critical infrastructures in the taxi system that are equipped with certain facilities including restaurants, toilets, lounges, parking lots and refuelling stations, and provide services such as vehicle washing, repair and maintenance. 
A taxi service centre location is affected by multiple factors such as the service demand, urban land constraints, and surrounding environment. The increase in the taxi service demand leads to diversified characteristics, and taxi service centres are requested to offer a variety of facilities and services. Different demands require different service intensities, and the survey found that demands for dining, parking and other services are large, while demands for vehicle repair and maintenance are relatively small. In addition, taxi operation in an urban road network exhibits dispersed characteristics, and the number of taxi service centres is also requested to be large. Furthermore, taxi service centres inevitably require appropriate land safeguards, though the land development in the old town is of high intensity and land is difficult to obtain. Therefore, to improve the utilization of the facilities and services, it is important to shorten the time to reach the taxi service centres, satisfy the land constraints, and achieve maximum benefits. Thus, taxi service centres should be equipped with differentiated service facilities.

Based on the above analysis, this study proposes a hierarchical layout mode for taxi service centres, which can be divided into three categories, namely, integrated service, functional service, and convenient service centres, as shown in Tab. 1.

Table 1 Process of receiving services in taxi service centres

\begin{tabular}{|c|l|l|l|}
\hline Grade & Classification & \multicolumn{1}{|c|}{$\begin{array}{l}\text { Functional } \\
\text { orientation }\end{array}$} & $\begin{array}{l}\text { Functions of service } \\
\text { facilities }\end{array}$ \\
\hline 1 & $\begin{array}{l}\text { Integrated } \\
\text { Service Centre } \\
\text { Provide } \\
\text { comprehensive } \\
\text { integrated services }\end{array}$ & $\begin{array}{l}\text { Parking, dining, } \\
\text { toileting, fuel } \\
\text { filling, charging, } \\
\text { vehicle } \\
\text { maintenance, } \\
\text { accreditation, etc. }\end{array}$ \\
\hline 2 & $\begin{array}{l}\text { Functional } \\
\text { Service Centre }\end{array}$ & $\begin{array}{l}\text { Shorten the time to } \\
\text { reach taxi service } \\
\text { centres }\end{array}$ & $\begin{array}{l}\text { Parking, dining, } \\
\text { toileting, fuel } \\
\text { filling, simple } \\
\text { vehicle } \\
\text { maintenance }\end{array}$ \\
\hline 3 & $\begin{array}{l}\text { Convenient } \\
\text { Service Centre }\end{array}$ & $\begin{array}{l}\text { Provide basic } \\
\text { services and meet } \\
\text { taxi operation } \\
\text { demand }\end{array}$ & $\begin{array}{l}\text { Parking, dining, } \\
\text { toileting }\end{array}$ \\
\hline \multirow{2}{*}{\begin{tabular}{l}
$\mid l$ \\
\hline
\end{tabular}}
\end{tabular}

\section{METHODOLOGY}

In this study, the taxi service centres are arranged step by step based on their rank and scale. The functional service centre layout is based on the layout of integrated service centres. Similarly, a convenient service centre layout is considered on the basis of the layouts of integrated service centres and functional service centres.

According to the existing layout planning practices for taxi service centres in China, the demands for integrated service centres are relatively few, generally being between one and three, and the layout is relatively simple. The number of convenient service centres is large and they can be located along with existing traffic service facilities flexibly. Therefore, qualitative analysis methods are used to determine the layout of the above service centres. However, functional service centres effectively connect integrated service centres and convenient service centres, the numbers and location of which are of tremendous significance in a taxi system, and they can determine to a certain degree whether relevant services can be obtained conveniently. Therefore, quantitative analysis methods are used to determine the layout of functional service centres, for which the layout model with capacity limitations is proposed.

\subsection{Determination of Alternative Taxi Service Centres}

Land use planning is often suggested prior to transportation planning in various Chinese cities. Land use planning for taxi service centres is implemented when the taxi service demand reaches a certain level. This case is particularly prevalent in an old town where land development intensity is significant. The limitations in the land resources will limit the locations of the taxi service centres to limited locations. Therefore, alternative stations should be determined before finalizing the taxi service centre layout.

In view of the old renewal and inventory planning in old towns, the construction of taxi service centres should revitalize stock resources to the maximum extent and make complete use of the existing traffic facilities, to save the construction cost, shorten the construction period and ensure taxi service centres are successfully implemented, as shown in Tab. 2.

Table 2 Layout highlights for alternative taxi service centres

\begin{tabular}{|c|c|c|}
\hline Classification & $\begin{array}{c}\text { Service radius and } \\
\text { scale }\end{array}$ & Layout highlights \\
\hline $\begin{array}{l}\text { Integrated } \\
\text { service center }\end{array}$ & $\begin{array}{c}R>5 \mathrm{~km}, \\
S>3000 \mathrm{~m}^{2}\end{array}$ & $\begin{array}{l}\text { (1) Avoid to locate in core area } \\
\text { of the old town; } \\
\text { (2) Combined with public } \\
\text { transport facilities and } \\
\text { refueling stations; } \\
\text { (3) The number of service } \\
\text { centers is recommended } 1-3 \text {. }\end{array}$ \\
\hline $\begin{array}{l}\text { Functional } \\
\text { service center }\end{array}$ & $\begin{array}{c}3<R \leq 5 \mathrm{~km}, \\
1000<S \leq 3000 \mathrm{~m}^{2}\end{array}$ & $\begin{array}{l}\text { (1) Combined with refueling } \\
\text { stations and vehicle } \\
\text { maintenance stations; } \\
\text { (2) Combined with taxi stops } \\
\text { that spontaneous formed; } \\
\text { (3) The number of taxi service } \\
\text { centers is recommended 4-7 }\end{array}$ \\
\hline $\begin{array}{l}\text { Convenient } \\
\text { service center }\end{array}$ & $\begin{array}{c}R \leq 3 \mathrm{~km} \\
S \leq 1000 \mathrm{~m}^{2}\end{array}$ & $\begin{array}{l}\text { (1) Set up limited-time special } \\
\text { parking space combining with } \\
\text { architecture back-space, } \\
\text { roadside parking resources, } \\
\text { etc. } \\
\text { (2) Service for taxi operation } \\
\text { combining with transportation } \\
\text { hub, tourist center, Business } \\
\text { center, etc. }\end{array}$ \\
\hline
\end{tabular}

\subsection{Mathematical Model 3.2.1 Model Construction}

The constraints of traffic location and land use limit the maximum capacity that can be attained during the construction of taxi service centres. To attract taxis to service centres and ensure operational benefits, the taxi service centres should also have a minimum capacity limit. Therefore, this study proposes a taxi service centre layout model under capacity limitations. Thus, the model selects some service centres from a set of alternative taxi service centres while meeting the capacity constraints.

Through the analysis of the taxi operation characteristics, this study finds that their uncertainty is high and the origin and termination vary with the passenger demand. The service demand exhibits the characteristics of 
single service objects, a centralized service time, and spatially dispersed objects. According to the survey about taxi-drivers receiving services in taxi service centres, we find that in most cases, the taxi-drivers make a special trip to the service centres, as shown in Fig. 1. Therefore, the research on taxi service demand can be transformed into the number of vacant taxis.

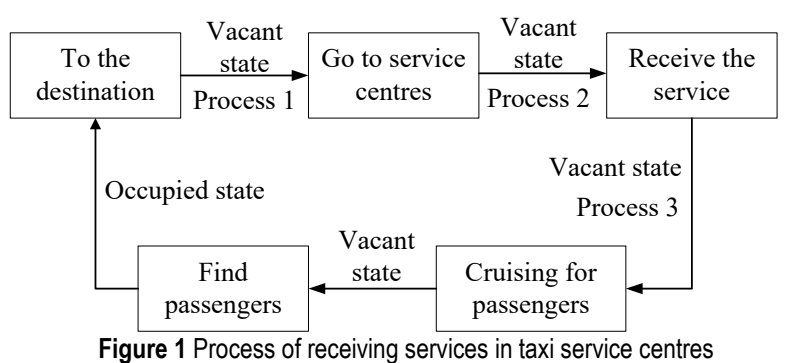

Existing studies have found that regarding the choice behaviour of the vacant taxi-drivers, drivers always attempt to obtain new passengers within the shortest possible time [30-33]. The service centre selection for the taxi drivers is related to three served processes. According to land-use property, the study area is divided into several traffic zones, which can be regarded as generating point and passenger demand point of vacant taxis. Following this, this study selects the optimal layout scheme from alternate taxi service centres.

Therefore, the objective of taxi service centre layout optimization is minimizing the total weighted time including the travel time from the traffic zones to taxi service centres, the time in which services are received from taxi service centres, and the time required to search for passengers from the taxi service centres, which can be expressed as follows.

$$
\min Z=\sum_{i \in A} \sum_{k \in M} X_{i k} T_{i k}+\sum_{k \in M} \sum_{i \in A} X_{i k} T_{k}+\sum_{k \in M} \sum_{j \in A} Y_{k j} T_{k j}
$$

Subject to:

$$
\begin{aligned}
& \sum_{k \in M} X_{i k}=\sum_{i \in A} Y_{k j} \\
& C_{k}^{\min } \leq \sum_{i \in A} X_{i k} \leq C_{k}^{\max } \\
& \sum_{k \in M} X_{i k} \geq Q_{i}, i \in 1,2, \cdots, A \\
& \sum_{i \in A} Y_{k j} \leq D_{j} \\
& \sum_{k=1}^{N} \varphi_{k} \leq N, \varphi_{k} \in\{0,1\} \\
& X_{i k} \geq 0, Y_{k j} \geq 0
\end{aligned}
$$

where $Z$ is the objective function, $A$ is the number of traffic zones, $Q_{i}$ is the taxi service demand of traffic zone $i, N$ is the number of alternative taxi service centres, $D_{j}$ is the passenger demand for a taxi of traffic zone $j, T_{k}$ is the time in which it receives service at the taxi service centres, $X_{i k}$ is the number of vacant taxis departing from traffic zone $i$ to alternative taxi service centre $k, T_{i k}$ is the shortest travel time from traffic zone $i$ to alternative taxi service centre $k$, $Y_{k j}$ is the number of vacant taxis departing from alternative taxi service centre $k$ to traffic zone $j, T_{k j}$ is the shortest travel time from alternative taxi service centre $k$ to traffic zone $j$, $C_{k}^{\min }$ and $C_{k}^{\max }$ are, respectively, the minimum and maximum scale constraints of the taxi service centres, and $\varphi_{k}$ is the Boolean variable, namely the decision variable in the model. If it is located in the alternative taxi service centre $k, \varphi_{k}=1$; otherwise, $\varphi_{k}=0$.

Eq. (2) implies that all the taxis leaving the service centres will search for passengers. Eq. (3) indicates that the taxi service centres are constrained by the scale capacity. Eq. (4) expresses that the taxi demand of the traffic zones does not exceed the number of vacant taxis departing from the traffic zones to the service centres. Eq. (5) displays that the number of vacant taxis departing from the service centres to the traffic zones does not exceed the taxi demand of the traffic zones, owing to the occupied taxis in the traffic zones that have undertaken a part of the demand. Eq. (6) represents the selected taxi service centres from the sets of alternative service centres.

\subsubsection{Model Solutions}

The model proposed in this study is essentially a mixed 0-1 integer programming problem. For simpler layout planning problems, the branch-bound method and cutting plane method can be used to obtain the optimal solution. For complex layout planning problems, the layout combinations exhibit a dramatic increase exponentially, and the computational efficiency reduces when the alternative service centres, constraint conditions or decision variables increase, which is a NP-hard problem that can only be solved by some heuristic algorithms [34, 35]. According to the existing studies, a genetic algorithm is a stochastic programming method with the characteristics of self-organization, self-adaption and selflearning [36, 37]. Therefore, this study uses genetic algorithms to solve the model, and the process is shown as follows.

- Step 1: Coding for variables. This study adopts the 01 coding method, the number of alternative taxi service centres $(N)$ is regarded as the length of chromosomes among which, 0 indicates that an alternative taxi service centre is not selected, and 1 indicates that it is selected.

- Step 2: Randomly generating initial population.

- Step 3: Constructing fitness function. This study aims to minimize the total weighted time, thus, assigns $f(i)$ $=U-Z(i) . f(i)$ represents the fitness of the $i^{\text {th }}$ individual, $U$ represents the constant value, which is large enough, and $U>\max \{Z(i)\}, Z(i)$ is the objective function value of the $i^{\text {th }}$ individual.

- Step 4: Constraint processing. This study selects two individuals randomly from the group, first determines whether the individual is a feasible solution, and if it does, calculates the fitness value; otherwise, calculates the extent to which it exceeds the constraint and then compares within the rule as follows:(1) When feasible solutions are compared, a high-valued is more possible to enter the next generation; (2) When feasible solutions are compared with infeasible solutions, the former enters the next generation with higher possibility; (3) When infeasible solutions are compared, the lower degree to which it exceeds the 
constraint, the higher possibility to enter the next generation.

- Step 5: Genetic operation. (1) Selection-first, rank the fitness from highest to lowest among all individuals, and rank infeasible solutions from lowest to highest based on the extent to which it exceeds the constraint, then select the next generation based on the roulette method; (2) Crossover-set crossover probability and perform single-point crossover operation to create new individual; (3) Mutationaccording to the mutation probability, select one position of chromosomes for mutation, and select any position being 1 of the chromosome randomly for mutation.

- Step 6: Stopping criteria. This study designs two criteria: (1) Define calculator $V$, when $\min \left(Z^{V}\right)<\min$ $\left(Z^{V+1}\right), \min \left(Z^{V+1}\right)=\min \left(Z^{V}\right), V=V+1$, return to the calculation, otherwise the algorithm ends; (2) Define the minimum number of iterations $S$, when the number of offspring exceeds $S$, the algorithm ends.

\section{CASE STUDY}

This study hereby assigns to the jour Jiangning district, with a land area of $1558 \mathrm{~km}^{2}$, a population of more than 950 thousand people. Currently, the taxi fleet size is 1008 vehicles. In Dongshan vice city, the central urban area of the Jiangning district, taxis exert considerable demands on the limited road space even when they are empty and cruising for passengers. In this study, the downtown area of Jiangning distric-Dongshan vice city is used as a case study to understand the taxi service centre layout planning.

For integrated service centres, qualitative analysis methods are adopted. Considering the proposed layout highlights listed in Tab. 2 and the development demands of new towns located in Shangfang area, the number of which is determined to be one, where, combining with public passenger transport service centre.

For functional service centres, quantitative analysis methods are adopted. Based on the available inventory land in Dongshan, the number of alternative taxi service centres is determined to be seven. Based on the survey, their capacity can be obtained, as listed in Tab. 3 .

Table 3 The capacity constraints of alternative taxi service centres

\begin{tabular}{|c|c|c|c|}
\hline $\begin{array}{c}\text { Alternative taxi } \\
\text { service centres }\end{array}$ & $C_{k}^{{ }^{m i n}}(\mathrm{veh})$ & $C_{k}^{\max }(\mathrm{veh})$ & The nature of land use \\
\hline $\mathrm{A}$ & 60 & 75 & Parking lot \\
\hline $\mathrm{B}$ & 35 & 45 & Refuelling station \\
\hline $\mathrm{C}$ & 25 & 40 & Passenger station \\
\hline $\mathrm{D}$ & 20 & 30 & Refuelling station \\
\hline $\mathrm{E}$ & 50 & 75 & Refuelling station \\
\hline $\mathrm{F}$ & 45 & 60 & Passenger station \\
\hline $\mathrm{G}$ & 40 & 70 & Passenger station \\
\hline
\end{tabular}

To determine the number of vacant taxis, Dongshan vice city is divided into seven traffic zones based on the Controlled Detailed Planning and Comprehensive Transportation Planning of Jiangning District, as shown in Fig. 2.

The number of vacant taxis in a planning year is related to the population, taxi fleet size, share rate, and vacant rate. Based on the Public Transport Development Planning of Jiangning District and taxi operation survey data, the number of generated taxis and passenger demand in 2020 can be analysed, as shown in Tab. 4. The shortest time from traffic zones to alternative taxi service centres can also be obtained, as shown in Tab. 5 .

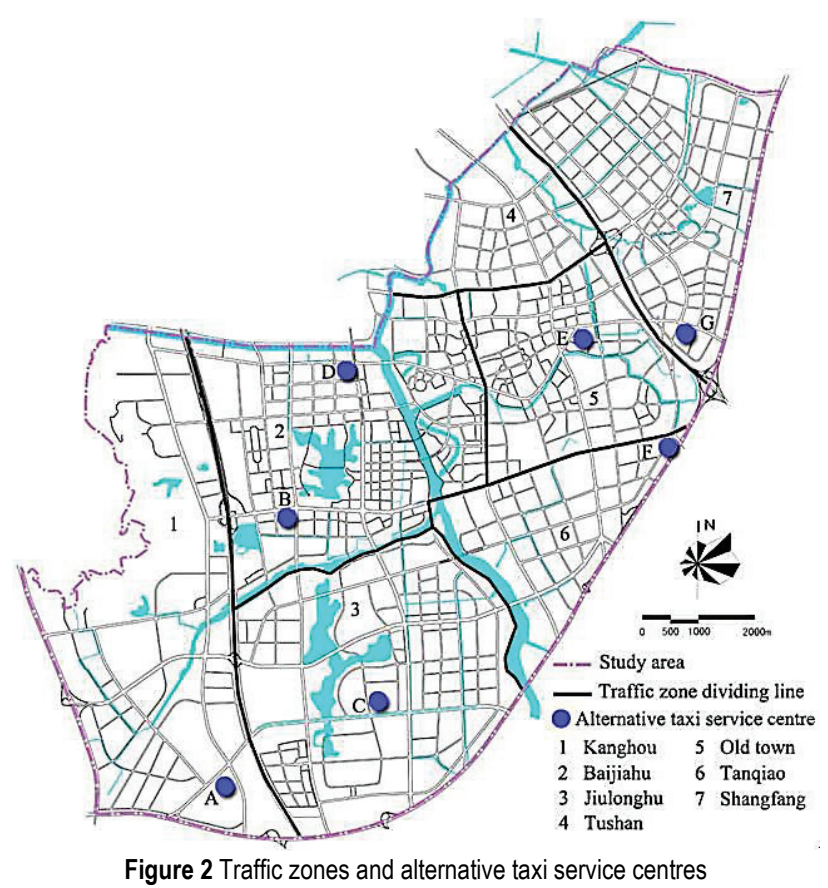

Table 4 Generation trip of taxis and passenger demand

\begin{tabular}{|c|c|c|c|}
\hline Traffic zone ID & $\begin{array}{c}\text { The number of } \\
\text { vacant taxis } \\
\text { (veh) }\end{array}$ & $\begin{array}{c}\text { Passenger } \\
\text { demand (veh) }\end{array}$ & Traffic zone ID \\
\hline 1 & 36 & 28 & 1 \\
\hline 2 & 40 & 53 & 2 \\
\hline 3 & 51 & 60 & 3 \\
\hline 4 & 23 & 19 & 4 \\
\hline 5 & 75 & 92 & 5 \\
\hline 6 & 42 & 31 & 6 \\
\hline 7 & 89 & 73 & 7 \\
\hline
\end{tabular}

Note: Assume that supply-demand is equilibrium under a regulated market.

Table 5 Time matrix of traffic zones to alternative taxi service centres

\begin{tabular}{|c|c|c|c|c|c|c|c|}
\hline & $\mathrm{A}$ & $\mathrm{B}$ & $\mathrm{C}$ & $\mathrm{D}$ & $\mathrm{E}$ & $\mathrm{F}$ & $\mathrm{G}$ \\
\hline 1 & 6.57 & 5.90 & 8.81 & 12.35 & 18.75 & 20.49 & 23.87 \\
\hline 2 & 13.82 & 4.37 & 9.80 & 3.28 & 8.63 & 11.54 & 14.02 \\
\hline 3 & 7.64 & 6.48 & 2.36 & 11.43 & 13.84 & 13.54 & 17.63 \\
\hline 4 & 24.06 & 14.57 & 19.21 & 8.07 & 5.40 & 10.62 & 9.10 \\
\hline 5 & 21.73 & 13.92 & 15.89 & 9.56 & 2.41 & 4.23 & 4.35 \\
\hline 6 & 16.54 & 11.21 & 10.41 & 10.31 & 6.48 & 4.45 & 8.80 \\
\hline 7 & 28.76 & 20.04 & 23.13 & 14.13 & 7.69 & 10.33 & 6.29 \\
\hline
\end{tabular}

Matlab software is used to program and solve the mathematical model, and optimization results of several combinations are obtained, as shown in Tab. 6 .

Table 6 Layout optimization results

\begin{tabular}{|c|c|c|}
\hline Number & Alternative taxi service centres & $\begin{array}{c}\text { Optimal total } \\
\text { time } / \text { min }\end{array}$ \\
\hline 4 & $\mathrm{~A}, \mathrm{~B}, \mathrm{D}, \mathrm{E}$ & $2.15 \times 10^{4}$ \\
\hline 4 & $\mathrm{~A}, \mathrm{D}, \mathrm{E}, \mathrm{F}$ & $2.19 \times 10^{4}$ \\
\hline 4 & $\mathrm{~B}, \mathrm{C}, \mathrm{E}, \mathrm{F}$ & $2.10 \times 10^{4}$ \\
\hline 5 & $\mathrm{~A}, \mathrm{~B}, \mathrm{C}, \mathrm{D}, \mathrm{E}$ & $2.33 \times 10^{4}$ \\
\hline 6 & $\mathrm{~A}, \mathrm{~B}, \mathrm{C}, \mathrm{D}, \mathrm{E}, \mathrm{F}$ & $2.48 \times 10^{4}$ \\
\hline 7 & $\mathrm{~A}, \mathrm{~B}, \mathrm{C}, \mathrm{D}, \mathrm{E}, \mathrm{F}, \mathrm{G}$ & $2.71 \times 10^{4}$ \\
\hline
\end{tabular}

It can be seen from the results that when the number of taxi service centres increases, the optimal total time 
increases. Therefore, we determine the number of taxi service centres to be four, and the optimal layout combination to be $\mathrm{B}, \mathrm{C}, \mathrm{E}$, and $\mathrm{F}$.

For convenient service centres, qualitative analysis methods are adopted. Based on the layout schemes of integrated and functional service centres, considering the service radius, land use and actual road conditions, the number of which is determined to be 23 , they were evenly located in Dongshan vice city combining with existing dining area, taxi stops, roadside parking resources, architecture back space and charging stations for new energy vehicles, as shown in Fig. 3.

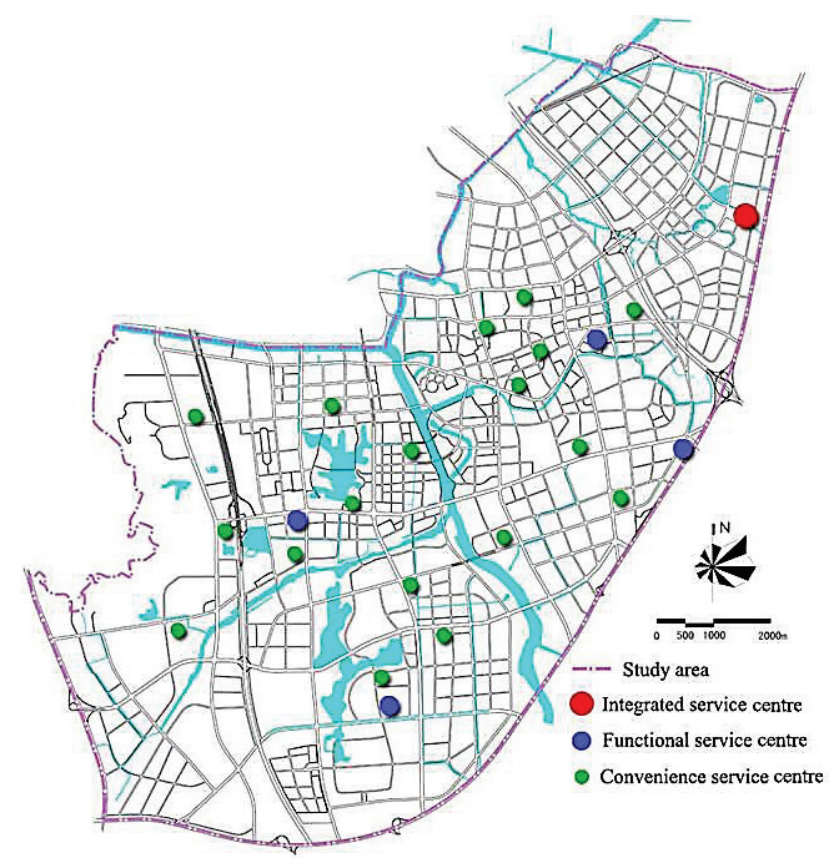

Figure 3 The layout scheme of taxi service centres

\section{CONCLUSION}

The layout planning of taxi service centres is of great significance for improving taxi drivers' health conditions and promoting sustainable transportation. This study found that taxi service centres should be equipped with differentiated service facilities to shorten the time to reach the taxi service centres, satisfy the land constraints, and achieve maximum benefits. Then, this study proposed a hierarchical layout mode, which divided taxi service centres into three categories - integrated service centres, functional service centres, and convenient service centres. This study proposed stepwise layout planning methods integrated with upgrading transportation facilities. The constrained layout model is established by optimizing the layout scheme among various alternative taxi service centres. The model is a mixed $0-1$ integer programming problem, genetic algorithms are applied to solve it. Finally, Jiangning district, Nanjing is taken as a case study to verify the proposed methods. The results show that taxi drivers' multiple demand could be satisfied by the calculation results - one integrated service centre, four functional service centres, and twenty-three convenient service centres. The results suggest that the proposed methods should effectively address the layout planning problem of taxi service centres, which could provide technical supports to city planners, and have important implications for other cities' downtown areas in China and beyond.

The contributions of the study to the literature are to introduce the term taxi service centres aiming to satisfy taxi drivers' multiple demand, and develop a new methodology based on stepwise layout planning method for taxi service centres. However, there are several limitations in the present study. First, uncertainty is one type of limitation that exists almost in every model, the uncertainty of the model will affect the layout optimization, thus, it is necessary to conduct an uncertainty analysis and quantify uncertainty effects of the model in future studies. Second, with the growth of car rentals on the internet, the choice behaviour and operation characteristics of taxi drivers may change, thus, the proposed methods should be improved. Third, each type of service centres are mutually linked, thus, the coordinated layout method should be further considered. Fourth, regarding convenient service centres combined with limited-time special parking spaces should also be further considered for an effective implementation. In addition, the impact that a taxi service centre may lay on the urban traffic is not considered, and a layout evaluation system should be established. Future studies are recommended to improve the deficiencies above.

\section{Acknowledgements}

There is no conflict of interests regarding the publication of this paper. This research is supported by the Panning Service Project for Transit Metropolis of Jiangning District, Nanjing, China (No. JNZC-2015061). The authors would like to thank Jiangning Transportation Bureau, Taxi Co. Ltd. and graduate students from Bluesky Studio, Southeast University for their assistance in data collection. The authors are grateful to editors and anonymous reviewers for raising constructive comments and suggestions on this paper.

\section{REFERENCES}

[1] Shaaban, K. \& Kim, I. (2016). Assessment of the taxi service in Doha. Transportation Research Part A: Policy and Practice, 88, 223-235. https://doi.org/10.1016/j.tra.2016.04.011

[2] Qian, X. W. \& Ukkusuri, S. V. (2015). Spatial variation of urban taxi ridership using GPS data. Applied Geography, 59, 31-42. https://doi.org/10.1016/j.apgeog.2015.02.011

[3] Lina, K., Alexre, D. B., \& Wirasinghe, S. C. (2010). Analysis of work trips made by taxi in Canadian cities. Journal of Advanced Transportation, 44(1), 11-18. https://doi.org/10.1002/atr.102

[4] Kang, C. G. \& Qin, K. (2016). Understanding operation behaviours of taxicabs in cities by matrix factorization. Computers, Environment and Urban Systems, 60, 79-88. https://doi.org/10.1016/j.compenvurbsys.2016.08.002

[5] Cai, H., Zhan, X. W., Zhu, J. et al. (2016). Understanding taxi travel patterns. Physica A: Statistical Mechanics and its applications, 457, 590-597. https://doi.org/10.1016/j.physa.2016.03.047

[6] Wong, R. C. P., Szeto, W. Y., Wong, S. C., \& Yang, H. (2014). Modelling multi-period customer-searching behaviour of taxi drivers. Transportmetrica B: Transport Dynamics, 2(1), 40-59. https://doi.org/10.1080/21680566.2013.869187

[7] Szeto, W. Y., Wong, R. C. P., Wong, S. C., \& Yang, H. (2013). A time-dependent logit-based taxi customer-search model. 
International Journal of Urban Sciences, 17(2), 184-198. https://doi.org/10.1080/12265934.2013.776292

[8] Arnott, R. (1996). Taxi travel should be subsidized. Journal of Urban Economics, 40(3), 316-333. https://doi.org/10.1006/juec.1996.0035

[9] Machin, M. A. \& Souza, J. D. (2004). Predicting health outcomes and safety behavior in taxi drivers. Transportation Research Part F: Psychology and Behaviour, 7(4-5), 257-27. https://doi.org/10.1016/j.trf.2004.09.004

[10] Daskin, M. S. (2013). Network and Discrete Location: Models, Algorithms, and Application. $2^{\text {nd }}$ Edition. John Wiley \& Sons Inc, New York, USA.

[11] Frade, I., Ribeiro, A., Goncalves, G., \& Antunes, A. P. (2011). Optimal location of charging stations for electric vehicles in a neighborhood in Lisbon, Portugal. Transportation Research Record: Journal of the Transportation Research Board, 2252, 91-98. https://doi.org/10.3141/2252-12

[12] Li, X. P., Zhao, Z. X., Zhu, X. Y., \& Wyatt, T. (2011). Covering models and optimization techniques for emergency response facility location and planning: a review. Mathematical Methods of Operations Research, 74(3), 281310. https://doi.org/10.1007/s00186-011-0363-4

[13] Berman, O. \& Krass, D. (2002). The generalized maximum covering location problem. Computers \& Operations Research, 29(6), 563-581. http://doi.org/10.1016/S0305-0548(01)00079-X

[14] Daskin, M. S. (1983). A maximum expected covering location problem: formulation, properties, and heuristic solution. Transportation Science, 17(1), 48-70. https://doi.org/10.1287/trsc.17.1.48

[15] Hassin, R., Levin, A., \& Morad, D. (2003). Lexicographic local search and the p-centre problem. European Journal of Operational Research, 151(2), 265-279. https://doi.org/10.1016/S0377-2217(02)00825-1

[16] Megiddo, N. \& Supowit, K. J. (1984). On the complexity of some common geometric location problems. Siam Journal on Computing, 13(1), 182-196. https://doi.org/10.1137/0213014

[17] Chen, D. \& Chen R. (2013). Optimal Algorithms for the $\alpha$ neighbor p-centre Problem. European Journal of Operation Research, 225(1), 36-43. https://doi.org/10.1016/j.ejor.2012.09.041

[18] Brimberga, J. \& Drezner Z. (2013). A new heuristic for solving the p-median problem in the plane. Computers \& Operations Research, 40(1), 427-437. https://doi.org/10.1016/j.cor.2012.07.012

[19] Hakimi, S. L. (1986). P-median theorems for competitive location. Annals of Operations Research, 6(4), 75-98. https://doi.org/10.1007/BF02032873

[20] Drezner, Z. (1995). Dynamic facility location: the progressive p-median problem. Location Science, 3(1), 1-7. https://doi.org/10.1016/0966-8349(95)00003-Z

[21] Kuby, M. \& Lim, S. (2005). The flow-refueling location problem for alternative-fuel vehicles. Socio-Economic Planning Sciences, 39(2), 125-145. https://doi.org/10.1016/j.seps.2004.03.001

[22] Kuby, M., Lines, L., Schultz R., \& Xie, Z. (2009). Optimization of hydrogen stations in Florida using the flowrefueling location model. International Journal of Hydrogen Energy, 34(15), 6045-6064. https://doi.org/10.1016/j.jijhydene.2009.05.050

[23] Berman, O. (1997). Deterministic flow-demand location problem. Journal of the Operational Research Society, 48(1), 75-81. https://doi.org/10.1038/sj.jors.2600324

[24] Zhang, L. \& Rushton, G. (2008). Optimizing the size and locations of facilities in competitive multi-site service system. Computers \& Operations Research, 35(2), 327-338. https://doi.org/10.1016/j.cor.2006.03.002

[25] Plastria, F. \& Vanhaverbeke, L. (2007). Aggregation without loss of optimality in competitive location models. Networks
\& Spatial Economics, 7(1), 3-18. https://doi.org/10.1007/s11067-006-9004-5

[26] Plastria, F. \& Vanhaverbeke, L. (2008). Discrete models for competitive location with foresight. Computers \& Operations Research, 35(3), 683-700. https://doi.org/10.1016/j.cor.2006.05.006

[27] Aboolian, R., Berman, O., \& Krass, D. (2007). Competitive facility location model with concave demand. European Journal of Operational Research, 181(2), 598-619. https://doi.org/10.1016/j.ejor.2005.10.075

[28] Hwang, S. W., Kweon, S. J., Sang, J., \& Ventura, J. A. (2017) Locating alternative-fuel refuelling stations on a multi-class vehicle transportation network. European Journal of Operational Research, 261(3), 941-957. https://doi.org/10.1016/j.ejor.2017.02.036

[29] Hosseini, M., MirHassani, S. A., \& Hooshmand, F. (2017). Deviation-flow refuelling location problem with capatitated facilities: model and algorithm. Transportation Research Part D: Transport and Environment, 54, 269-281. https://doi.org/10.1016/j.trd.2017.05.015

[30] Yang, H. \& Wong, S. C. (1998). A network model of urban taxi services. Transportation Research Part B: Methodological, 32(4), 235-246. https://doi.org/10.1016/S0191-2615(97)00042-8

[31] Wong, K. I., Wong, S. C., \& Yang, H. (2001). Modeling urban taxi services in congested road network with elastic demand. Transportation Research Part B: Methodological, 35(9), 819-842. https://doi.org/10.1016/S0191-2615(00)00021-7

[32] Yang, H., Wong, S. C., \& Wong, K. I. (2002). Demandsupply equilibrium of taxi services in a network under competition and regulation. Transportation Research Part B: Methodological, 36(9), 799-819. https://doi.org/10.1016/S0191-2615(01)00031-5

[33] Yang, H., Ye, M., Tang, W. H., \& Wong, S. C. (2005). Regulating taxi services in the presence of congestion externality. Transportation Research Part A: Policy and Practice, 39(1), 17-40. https://doi.org/10.1016/j.tra.2004.05.004

[34] Mirchandani, P. B., Rebello, R., \& Agnetis, A. (1995). The inspection station location problem in hazardous materials transportation: some heuristics and bounds. INFOR Information Systems \& Operational Research, 33(2), 100113. https://doi.org/10.1080/03155986.1995.11732271

[35] Levin, Y. \& Ben-Israel, A. (2004). A heuristic method for large-scale multi-facility location problems. Computers \& Operations Research, 31(2), 257-272. https://doi.org/10.1016/S0305-0548(02)00191-0

[36] Chambers, L. (1995). Practical Handbook of Genetic Algorithms: Applications. CRC Press, Boca Raton, Florida, USA. https://doi.org/10.1201/9781420050073

[37] Jaramillo, J. H., Bhadury, J., \& Batta, R. (2002). On the use of genetic algorithms to solve location problems. Computers \& Operations Research, 29(6), 761-779. https://doi.org/10.1016/S0305-0548(01)00021-1 


\section{Contact information:}

Zhenjun ZHU, Ph.D. Candidate

Jiangsu Key Laboratory of Urban ITS, Southeast University,

Jiangsu Province Collaborative Innovation Center of Modern Traffic,

Technologies, Southeast University,

School of Transportation, Southeast University

Jiangning District, Nanjing 211189, China

E-mail: zhuzhenjun@seu.edu.cn

Xiucheng GUO, Professor

(Corresponding author)

School of Transportation, Southeast University,

Jiangning District, Nanjing 211189, China

E-mail: seuguo@163.com

Jun ZENG, Ph.D. Candidate

School of Transportation, Southeast University,

Jiangning District, Nanjing 211189, China

E-mail: zengjun@seu.edu.cn

Yibang ZHANG, Ph.D. Candidate

School of Transportation, Southeast University,

Jiangning District, Nanjing 211189, China

E-mail: zhangyibang625@hotmail.com

Zhaoguo HUANG, Ph.D. Candidate

School of Civil Engineering, Lanzhou University of Technology,

Qilihe District, Lanzhou 730050, China

E-mail: seuhuang369@hotmail.com 